\title{
OPINION
}

\section{On environmental threats to male infertility}

\author{
Allen J Wilcox ${ }^{1}$ and Jens Peter E Bonde ${ }^{2}$
}

Asian Journal of Andrology (2013) 15, 199-200; doi:10.1038/aja.2012.153; published online 21 January 2013

$T_{1}^{\mathrm{h}}$ he possibility that environmental pollutants damage human fertility is a topic of both public concern and scientific interest. The effect of environmental factors on male fertility (semen parameters) has been a special focus, stimulated in part by the dramatic damage inflicted by the pesticide DBCP on testicular function. Extensive searches for testicular toxicants (in particular, the proposed effects of endocrine-disrupting compounds through fetal exposure) have produced little hard evidence of impairment in humans. This scarcity of evidence may reflect the difficulties of studying human fertility. Future fertility studies should consider the wide spectrum of environmental exposures that plausibly affect reproduction.

The idea that human fertility might be damaged by environmental contaminants has captured the imagination of such eminent writers as PD James (The Children of Men) and Margaret Atwood (A Handmaid's Tale). These novelists provide stark and dystopian visions of societies coping with fertility decline. It is no wonder that the scientific question of environmental damage to human fertility continues to attract public attention-even as the question itself remains stubbornly difficult to address.

It was the late 1970s when environmental toxicants first became widely recognized as a threat to human fertility. Industrial and agricultural workers who were exposed to the pesticide dibromo-chloropropane (DBCP) were discovered to be azoospermic. ${ }^{1,2}$ This evidence of testicular damage, supported by toxicological research in rodents, ${ }^{3}$ led to swift scientific consensus that $\mathrm{DBCP}$ was a human reproductive toxicant. DBCP production was suspended.

${ }^{1}$ Epidemiology Branch, National Institute of Environmental Health Sciences, Durham, NC 27709-2233, USA and ${ }^{2}$ Department of Occupational and Environmental Medicine, University Hospital of Copenhagen, Copenhagen, NV DK-2400, Denmark

Correspondence: Dr AJ Wilcox (wilcox@niehs.nih.gov) Received: 30 November 2012; Accepted: 30 November 2012; Published online: 21 January 2013
This discovery raised a further question: was DBCP a special case, or is testicular function broadly sensitive to industrial pollutants? The question prompted a wave of studies in the United States and Europe to explore diverse chemical exposures for possible testicular toxicity. These studies were largely negative, or with subtle findings that were seldom corroborated (for reviews, see Refs. 4-6). As a workplace exposure, DBCP appears to be atypical in its strong testicular effects, rather than the tip of an iceberg.

Scientific attention to testis toxicology faded, only to be revived in 1992 by publication of a review of sperm-quality data by Carlsen and colleagues. ${ }^{7}$ Their summary of semen analyses across six decades suggested a disturbing decline of human sperm count. Limitations of these retrospective data prompted vigorous criticism of the paper ${ }^{8,9}$ and the paper might have had less impact were it not for a provocative hypothesis that emerged to explain itthe 'estrogen hypothesis'. ${ }^{10}$ Toxicological research had already shown that many environmental chemicals are weakly estrogenic. ${ }^{11}$ The estrogen hypothesis proposed that environmental estrogens might be able to reduce the number of Sertoli cells in the male fetus through negative feedback of pituitary FSH secretion, thus impairing subsequent fertility. ${ }^{12}$

In pursuing this hypothesis, researchers found that the direct estrogenic activity of environmental contaminants is generally too weak to damage human fetal testicular development. ${ }^{13}$ Nonetheless, there is ample evidence that various environmental chemicals at extremely low levels (and perhaps in concert with one another) might interfere with hormone signalling, especially during critical phases of fetal and childhood development. ${ }^{14}$ While the estrogen hypothesis faded, the more general hypothesis of 'endocrine disruption' has emerged as highly influential in environmental toxicology and epidemiology. Since the mid-1990s, nearly 4000 scientific papers have been published on aspects of environmental endocrine disruptors and their possible consequences for a broad spectrum of health effects.

The specific relevance of endocrine-disrupting compounds to male fertility in humans, however, remains to be established. Damage by endocrine disruptors to the male reproductive tract of laboratory animals is difficult to extrapolate to humans, given species-specific differences in key biological mechanisms. ${ }^{15}$ The assessment of fertility in men presents its own problems, and findings have been mixed. For example, studies of persistent environmental pollutants and impaired testicular function in humans have been mostly negative, ${ }^{16}$ but this does not rule out possible effects from exposures earlier in development. One observational study (from Seveso, Italy) has been able to examine sperm counts in relation to direct measures of early-life exposure to an endocrine disruptor. ${ }^{17}$ Sperm counts were lower in the sons of mothers who had been exposed to dioxin and who breastfed their sons. These findings are of great interest, but with no opportunities for replication. The fact that such studies have proven so difficult points to the complexity of the biology-but perhaps also to the elusiveness of the effect being sought. Can so elusive an effect have important public health consequences? At present, there is no scientific consensus.

The endocrine disruption hypothesis has been extended to male reproductive end points beyond fertility. ${ }^{18}$ Exposures to endocrine disruptors in fetal life have been proposed to affect a range of male reproductive disorders including testicular cancer, cryptorchidism and hypospadias. There are tantalizing clues in support of this hypothesis: testicular cancer is one of the few types of cancer to have increased over the past 50 years, ${ }^{19}$ and factors operating in utero have been linked to lower sperm concentration and cryptorchidism in humans. ${ }^{20,21}$ The possibility of a generalized 'testicular dysgenesis syndrome' has been supported by some experimental work ${ }^{22-24}$ if not all. ${ }^{25}$ Even so, epidemiologic data do not support the presence of shared endocrine- 
related causes of these disparate testicular outcomes. $^{26,27}$ These discouraging results have led some to question whether the testicular dysgenesis syndrome in fact offers a coherent approach to testicular-related human disorders. ${ }^{28,29}$

More broadly, we know remarkably little about the most important question of all: the status of human fertility. Even if we can demonstrate biological mechanisms by which environmental pollutants might impair human fertility, what evidence is there that damage actually occurs? It would be enormously useful to know whether human fecundability (defined as the chance of conception in a given menstrual cycle) has declined over time. Unfortunately, valid estimates of fecundability are nearly impossible to reconstruct retroactively. ${ }^{30}$ Prospective studies face their own serious obstacles, especially for the detection of relatively mild effects. ${ }^{31}$ Still, if useful information could be provided by prospective fecundability studies (perhaps in the Scandinavian countries or China, where conditions for unbiased studies are more favorable), then such studies should be conducted. We know of no serious discussions of doing so.

Retrospective studies of human semen parameters are similarly fraught, although by a different set of problems having to do with participant selection, semen sampling and laboratory protocols. Once again, prospective studies are more trustworthy. A recently published prospective study by Skakkebak and colleagues, ${ }^{32}$ begun in Denmark in 1996, is exemplary. Such data do not rule out the possibility that sperm characteristics have declined in previous decades, but the study shows no evidence of decay of semen quality during the 15-year period of observation. Sperm quality may even have improved. Similar prospective studies are needed in diverse settings.

Even if effective monitoring studies were to show no decay in human reproductive capacity, good arguments can be made for research into preventable causes of infertility. Many prenatal and postnatal exposures-not necessarily related to endocrine disruption-could plausibly impair fertility. Reduced sperm counts have been reported (if not consistently) among the sons of mothers who smoke during pregnancy. ${ }^{33-35}$ Prenatal vitamin deficiencies, infections and medications all have well-known effects on human development, and could be harmful to fertility as well. The large birth cohorts established in Denmark and Norway over the past 20 years $^{36,37}$ are an important resource for new fertility studies - particularly with biological samples collected during fetal life that can be used to assess early exposures.

Endocrine disruptors are good candidates for investigation as reproductive toxicants in fetal life, but hardly the only ones. Human fertility is an intricate process, vulnerable to damage at many steps along the way. As we capitalize on new research opportunities to assess environmental threats to human fertility, we would be wise not to put all our eggs (or sperm) into one basket. If the history of fertility research has taught us anything, it is that reproductive toxicants come in many guises. We will be well served by a range of hypotheses that are equally diverse.

\section{COMPETING FINANCIAL INTERESTS}

All authors declare that there are no competing financial interests.

\section{ACKNOWLEDGMENTS}

We thank Donna Baird, Gwen Collman, John Bucher, Russ Hauser, Jerry Heindel, Morten Jensen, Ken Korach, Matthew Longnecker, Jørn Olsen and Walter Rogan for useful comments on previous versions of this

commentary. This work was supported by the Intramural Research Program of the NIH, National Institute of Environmental Health Sciences, and by a grant from the Danish Medical Research Council (10-082745).

1 Whorton MD, Krauss RM, Marshall S, Milby TH. Infertility in male pesticide workers. Lancet 1977; 2: $1259-61$.

2 Potashnik G, Ben-Aderet N, Israeli R, Yanai-Inbar I, Sober I. Suppressive effect of 1,2-dibromo-3chloropropane on human spermatogenesis. Fertil Steril 1978; 30: 444-7.

3 Babich H, Davis DL, Stotzky G. Dibromochloropropane (DBCP): a review. Sci Total Environ 1981; 17: 207-21.

4 Schrader SM. Occupational hazards to male reproduction. Occup Med 1994; 9: 405-14.

5 Baranski B. Effects of the workplace on fertility and related reproductive outcomes. Environ Health Perspect 1993; 101(Suppl 2): 81-90.

6 Bonde JP, Giwercman A. Occupational hazards to male fecundity. Reprod Med Rev 1995; 4: 59-73.

7 Carlsen E, Giwercman A, Keiding N, Skakkebaek NE. Evidence for decreasing quality of semen during past 50 years. BMJ 1992; 305: 609-13.

8 Fisch H, Goluboff ET. Geographic variations in sperm counts: a potential cause of bias in studies of semen quality. Fertil Steril 1996; 65: 1044-6.

9 Olsen GW, Bodner KM, Ramlow JM, Ross CE, Lipschultz LI. Have sperm counts been reduced 50 percent in 50 years? A statistical model revisited. Fertil Steril 1995; 63: 887-93.

10 Sharpe RM. Declining sperm counts in men-is there an endocrine cause? J Endocrinol 1993; 136: 357-60.

11 Colborn T, Clement C. Chemically-Induced Alterations in Sexual and Functional Development: The Wildlife/ Human Connection. Advances in Modern Environmental Toxicology. Vol. XXI. Princeton, NJ: Princeton Scientific Publishing Co., Inc.; 1992.

12 Sharpe RM, Skakkebaek NE. Are oestrogens involved in falling sperm counts and disorders of the male reproductive tract? Lancet 1993; 341: 1392-5.

13 Sharpe RM. The 'oestrogen hypothesis'-where do we stand now? Int J Androl 2003; 26: 2-15.

14 Kavlock RJ, Daston GP, DeRosa C, Fenner-Crisp P, Gray LE, Kaattari S et al. Research needs for the risk assessment of health and environmental effects of endocrine disruptors: a report of the U.S. EPAsponsored workshop. Environ Health Perspect 1996; 104(Suppl 4): 715-40.

15 Johnson KJ, Heger NE, Boekelheide K. Of mice and men (and rats): Phthalate-induced fetal testis endocrine disruption is species-dependent. Toxicol Sci 2012; 129: 235-48.

16 Bonde JP, Toft G, Rylander L, Rignell-Hydbom A, Giwercman $A$ et al. Fertility and markers of male reproductive function in Inuit and European populations spanning large contrasts in blood levels of persistent organochlorines. Environ Health Perspect 2008; 116: 269-77.

17 Mocarelli P, Gerthoux PM, Needham LL, Patterson DG $\mathrm{Jr}$, Limonta $\mathrm{G}$ et al. Perinatal exposure to low doses of dioxin can permanently impair human semen quality. Environ Health Perspect 2011; 119: 713-8.

18 Asklund C, Jørgensen N, Kold Jensen T, Skakkebaek $\mathrm{NE}$. Biology and epidemiology of testicular dysgenesis syndrome. BJU Int 2004; 93(Suppl 3): 6-11.

19 Purdue MP, Devesa SS, Sigurdson AJ, McGlynn KA. International patterns and trends in testis cancer incidence. Int J Cancer 2005; 115: 822-7.

20 Jensen MS, Toft G, Thulstrup AM, Henriksen $\mathrm{TB}$, Olsen $\mathrm{J}$ et al. Cryptorchidism concordance in monozygotic and dizygotic twin brothers, full brothers, and half-brothers. Fertil Steril 2010; 93: 124-9.

21 Storgaard L, Bonde JP, Ernst E, Andersen CY, Spano M et al. Genetic and environmental correlates of semen quality: a twin study. Epidemiology 2006; 17: 674-81.

22 Welsh M, Saunders PT, Fisken M, Scott HM, Hutchison GR et al. Identification in rats of a programming window for reproductive tract masculinization, disruption of which leads to hypospadias and cryptorchidism. J Clin Invest 2008; 118: 1479-90.

23 Mahood IK, Scott HM, Brown R, Hallmark N, Walker M et al. In utero exposure to di(n-butyl) phthalate and testicular dysgenesis: comparison of fetal and adult end points and their dose sensitivity. Environ Health Perspect 2007; 115(Suppl 1): 55-61.

24 Sharpe RM. Pathways of endocrine disruption during male sexual differentiation and masculinization. Best Pract Res Clin Endocrinol Metab 2006; 20: 91-110.

25 Mitchell RT, Childs AJ, Anderson RA, van den Driesche S, Saunders PT et al. Do phthalates affect steroidogenesis by the human fetal testis? Exposure of human fetal testis xenografts to di-n-butyl phthalate. J Clin Endocrinol Metab 2012; 97: E341-8.

26 Vidaeff AC, Sever LE. In utero exposure to environmental estrogens and male reproductive health: a systematic review of biological and epidemiologic evidence. Reprod Toxicol 2005; 20: 5-20.

27 Storgaard L, Bonde JP, Olsen J. Male reproductive disorders in humans and prenatal indicators of estrogen exposure: a review of published epidemiological studies. Reprod Toxicol 2006; 21: 4-15.

28 Akre 0 , Richiardi L. Does a testicular dysgenesis syndrome exist? Hum Reprod 2009; 24: 2053-60.

29 Thorup J, McLachlan R, Cortes D, Nation TR, Balic A et al. What is new in cryptorchidism and hypospadiasa critical review of the testicular dysgenesis hypothesis. J Pediatr Surg 2010; 45: 2074-86.

30 Sallmén $M$, Weinberg $C R$, Baird $D D$, Lindbohm ML, Wilcox AJ. Has human fertility declined over time?: why we may never know. Epidemiology 2005; 16: 494-9.

31 Bonde JP, Joffe M, Sallmén M, Kristensen P, Olsen J et al. Validity issues relating to time-to-pregnancy studies of fertility. Epidemiology 2006; 17: 347-9.

32 Jørgensen $N$, Joensen UN, Jensen TK, Jensen MB, Almstrup $\mathrm{K}$ et al. Human semen quality in the new millennium: a prospective cross-sectional populationbased study of 4867 men. BMJ Open 2012; 2: e000990.

33 Mamsen LS, Lutterodt MC, Andersen EW, Skouby SO, Sorensen KP et al. Cigarette smoking during early pregnancy reduces the number of embryonic germ and somatic cells. Hum Reprod 2010; 25: 2755-61.

34 Storgaard L, Bonde JP, Ernst E, Spanô M, Andersen $\mathrm{CY}$ et al. Does smoking during pregnancy affect sons' sperm counts? Epidemiology 2003; 14: 278-86.

35 Ramlau-Hansen $\mathrm{CH}$, Thulstrup AM, Storgaard L, Toft $\mathrm{G}$, Olsen $\mathrm{J}$ et al. Is prenatal exposure to tobacco smoking a cause of poor semen quality? A follow-up study. Am J Epidemiol 2007; 165: 1372-9.

36 Magnus P, Irgens LM, Haug K, Nystad W, Skjaerven R et al. MoBa Study Group. Cohort profile: the Norwegian Mother and Child Cohort Study (MoBa). Int J Epidemiol 2006; 35: 1146-50.

37 Olsen J, Melbye M, Olsen SF, Sørensen TI, Aaby P et al. The Danish National Birth Cohort-its background, structure and aim. Scand J Public Health 2001; 29: 300-7. 